\title{
Census methodology in Turkey: Transformation from traditional to register-based administrative data
}

\author{
Şebnem Beşe Canpolat* and Muharrem Gürleyen Gök \\ Turkish Statistical Institute, Ankara, Turkey
}

\begin{abstract}
With the goal of producing timelier, more useful, sustained and less costly annual population statistics, the Turkish Statistical Institute (TurkStat) plans to change its census methodology from combined to register-based. It also plans to produce census data on $1 \mathrm{~km}^{2}$ grids, in 2021. Turkstat's shift to a register-based census is also driven by Eurostat's goal of producing census variables annually in the post-2021 period, unfavorable features of previous census methods (traditional or combined), and significant improvements in national administrative registers. TurkStat plans to establish an integrated system that includes related registers for Turkey's 2021 Population and Housing Census (PHC). TurkStat's Address Based Population Registration System is sufficient to meet almost all the country's population statistical needs, except for labor force statistics and building and dwelling characteristics. Thus, TurkStat must carry out further research to set up a qualified database. With respect to the United Nations Economic Commission for Europe's recommendations for the 2020 PHCs, as well as European Union (EU) regulations, TurkStat is likely to produce approximately $70 \%$ of the core census topics using the currently available registers. With the 2021 PHC approaching, TurkStat's aim is to increase the quality and variety of register-based statistics.
\end{abstract}

Keywords: Traditional census, combined census, register-based census, Turkey

\section{Introduction}

\subsection{Demographic and population characteristics of Turkey}

The Republic of Turkey is a transcontinental country, located both in Asia and Europe, with a surface area of $769.604 \mathrm{~km}^{2}$. In 1927, when the first official population census was carried out in Turkey, the population was 13.6 million people. At 31 December 2018, the population was 82 million people [9]. Out of the 235 countries in the world, Turkey is currently ranked as the 19th largest population [1]. It has a larger population than 27 of the 28 European Union (EU) member states [2].

\footnotetext{
* Corresponding author: Şebnem Beşe Canpolat, Turkish Statistical Institute, Necatibey Cad. No:114, 06580, Ankara, Turkey. Tel.: +90 31245470 83; Fax: +90 31242555 79; E-mail: sebnem. canpolat@tuik.gov.tr.
}

According to Turkey's Address Based Population Registration System (ABPRS), in 2018, approximately 93\% of the country's population live in province and district centers. The population size has been increasing each year, but the rate of growth has not remained stable (see Fig. 1). In 2018, the population growth rate was $1.5 \%$ and it is estimated to decrease to $1.1 \%$ in 2025.

Turkey's 2018 population is the youngest of all European countries, with $67.8 \%$ of the population being of working age and only $8.8 \%$ aged 65 years or older [9]. Moreover, with a median age of 32.0 years, Turkey ranks as the 106th youngest out of 221 countries in the world [3]. Although Turkey's population is still relatively young, the proportion of Turkish citizens that are aged 65 years or older has been increasing faster than other European countries.

\subsection{Official statistics programme}

The Statistics Law of Turkey (Nr. 5429) was enacted in 2005 in order to establish a legal framework 


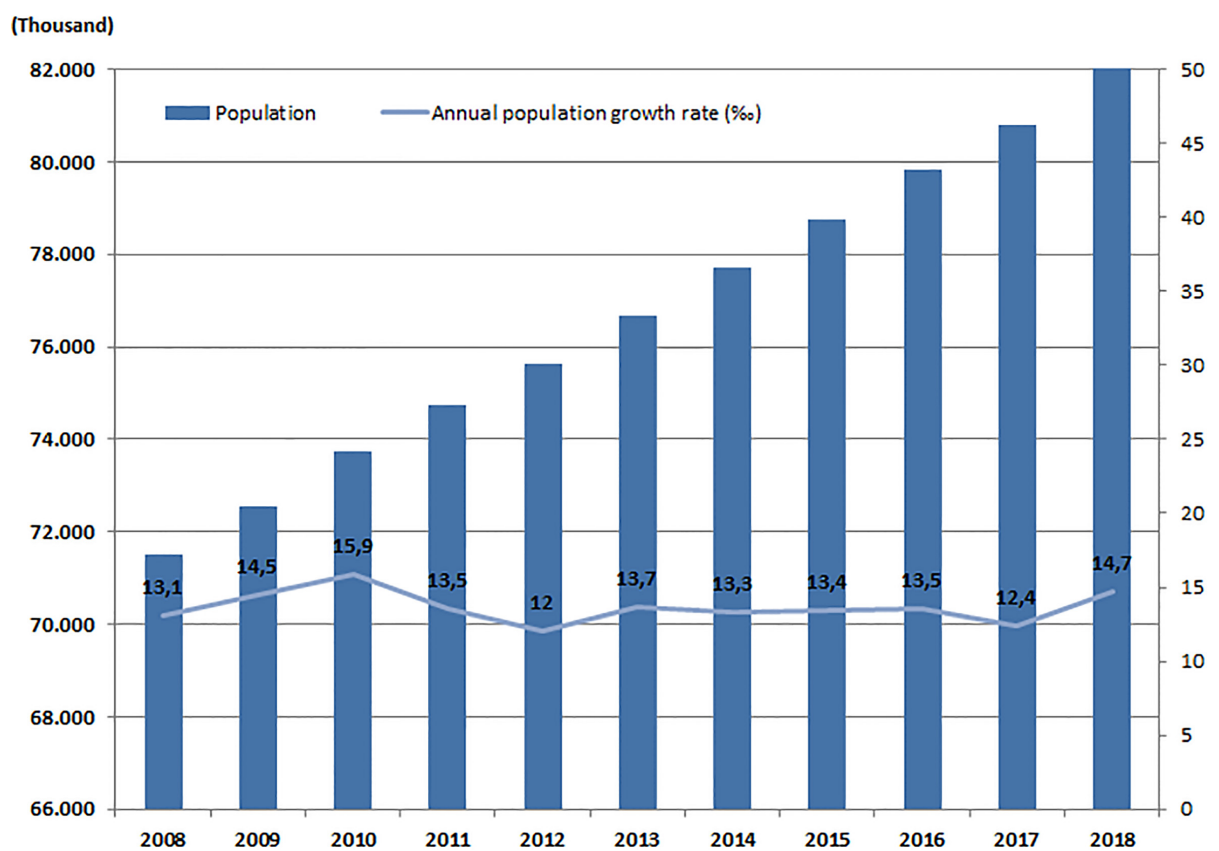

Fig. 1. Population size and population growth rate of Turkey, 2008-2018 [9].

for producing consistent, comparable, regular, and sustained official statistics for the country. This law regulates not only the Turkish Statistical Institute (TurkStat) but all the institutions in the Turkish statistical system. In accordance with this law, an Official Statistics Programme (OSP) is prepared by the Turkish Statistical Institute and the Statistical Council for each five-year period [4]. The current OSP covers the period from 2017 to 2021.

The OSP guides all statistical activities conducted by TurkStat, including the population census. The Statistics Law of Turkey gives TurkStat the authority to determine the statistical methods, definitions, classifications and standards to be used in the production of official statistics, in line with national and international norms. Therefore, TurkStat does not need a special census law.

\subsection{History of population censuses in Turkey}

Making policies and plans, such as identifying public investment and service needs, depends on the public administration's timely access to both quantitative and qualitative population information. There is no doubt that one of the main sources for such information is a population census. However, in some respects, the main purposes of censuses conducted long ago were different from modern censuses.

\subsubsection{Censuses in the Ottoman Empire}

The collection of information about the population during the Ottoman Empire can be divided into two separate periods. In the first period, from the 15 th to 19th century, the administration's main concerns were related to keeping their large country under close central control. Thus, the Empire used census-like surveys to collect information for tax and military purposes [5]. The 1831 census, which was accepted as the first population census, was carried out for the purpose of taxation and military reform. Therefore, only the male population of military age was included [6]. According to the archives, regional or general censuses were also carried out in the Ottomans, such as the censuses of $1844,1856,1866$, and 1874 for other interests in the treasury, army, and cadastral ministries. The 1885 and 1907 censuses marked the second period of population data collection in the Empire, when the objective was more focused on the administration of population services [5].

\subsubsection{Traditional censuses in the Turkish Republic}

The first population census of the Turkish Republic was conducted in 1927, four years after the declaration of the Republic. Subsequent population censuses were carried out every five years between 1935 and 1990. After the 1990 census, a decree was taken by the government to make a census every ten years. 
The last census was carried out in the year 2000. All 14 censuses in this period were conducted according to the traditional "de facto" census method, which enumerates people at the localities where they are physically present on census day. To ensure every individual was counted, Turkey implemented a national curfew on census day, ordering each person to remain at their current residence. On census day, the enumerators visited all residential addresses across Turkey and completed paper questionnaires via face-to-face interviews with residents. Both households and other residential places like dormitories, military barracks, prisons, hospitals, hotels etc. were included. In addition, nomadic communities were also counted.

In the 2000 population census, an optical-based data entry system was used to transfer the data to a digital format for the first time. This new system used the Optical Mark Recognition, Optical Character Recognition and Intelligent Character Recognition (ICR) technologies. Total data processing and dissemination took around 3.5 years and required about one million employees, including enumerators, supervisors, trainers and TurkStat staff [7].

In the absence of reliable data from the population registration system, planning and administration of public services relied on traditional population censuses as the main sources of data on population size and characteristics (e.g., age and sex). For example, census data was used to allocate each municipality's share of the general budget tax revenue. Similarly, identifying the need for new schools and hospitals, and maintaining public utilities like water, sewage, and electricity all depended on the census results. However, there were significant drawbacks to the traditional methodology, including high cost, complaints about curfew application, over-counting (e.g., including tourists present on census day), and the fact that information could only be collected on the enumeration date. Along with increasing data needs for the interim years, these reasons forced TurkStat to set up a population register with residential address information.

\subsubsection{Development of the address based population registration system}

Between 1997 and 1999, the Turkish Ministry of Interior established the Central Civil Registration System (MERNIS), which involved transferring civil records from paper-based family ledgers to a digital format. By the end of 2000, all Turkish citizens were given a unique 11-digit identification (ID) number. By the end of 2002, all civil registration offices in the country were connected to each other via an online network [8]. Although MERNIS is a centrally administered system, with any changes in civil status registered electronically in real time, the civil registration offices still had no information available on place of usual residence. As such, TurkStat could not use MERNIS for the 2000 population census.

The Turkish government established the ABPRS in 2006. The ABPRS was regulated by the Civil Registration Services Law, which gave TurkStat responsibility for developing the system and made the Ministry of Interior responsible for maintaining the system. Research and data collection for the ABPRS began in May 2006. The first step was to develop the National Address Database (NAD), which covers all addresses in the country. The NAD was created by the municipalities, in coordination with TurkStat, and includes names and unique codes for all localities, quarters, streets and buildings, as well as all independent units in each building. The NAD also records the type of each address/living quarter (e.g., residence, office, school, hospital etc.). Next, a full field enumeration was carried out to determine the usual residences of all Turkish citizens and foreigners living in the country. This information was matched with MERNIS by using the ID numbers previously allocated to each Turkish citizen. After establishment of the ABPRS by TurkStat, it was transferred to the Ministry of Interior in August 2007.

The ABPRS is not a statistical database; it is an administrative data source for all public institutions. For example, the Ministry of Health uses it to maintain the family medicine system, the Ministry of Education uses it to enroll pupils in the schools, and the Supreme Election Committee uses the ABPRS to create voter lists. Moreover, allocation of the general budget tax revenue shares to the municipalities is now based on the ABPRS. To keep the system up-to-date, fines are issued to people who do not notify the district civil registration offices of new or incorrect addresses. Turkish nationals and foreigner residents are required to make address change notification within 20 working days.

In accordance with the OSP, population size and basic population characteristics of all regions, provinces, districts, municipalities, villages, and quarters have been produced and announced annually since 31 December 2007. TurkStat is continuously trying to improve the statistics obtained from the ABPRS. In 2018, statistics on the following topics were available [9]: population size by locality, and urban/rural population; age and sex; literacy and highest level of education; 
place of civil registration; internal migration; immigration and emigration; country of citizenship; legal marital status; place/country of birth; household type and size; and birth and death statistics.

Improvements in the ABPRS have not only resulted in increasing the diversity of available statistics but, by using administrative data instead of household surveys, have also enabled the calculation of new statistics such as population projections and life tables.

\subsubsection{Population and Housing Census}

The 2011 Population and Housing Census (PHC) used a combined method to produce census-type statistics that were absent in the ABPRS or unavailable in household surveys with the necessary geographic detail. Therefore, the 2011 PHC collected data on building and housing characteristics, de-facto marital status, reason for migration, ever resided abroad and year of arrival in Turkey, disability, pre-school attendance, labor force status, employment status, and other occupation related variables.

A large-scale field survey, using a representative population sample, was implemented between October and December in 2011. Enumeration areas for the PHC were determined using data from the NAD, and each enumeration area included about 100 occupied dwellings. After defining the enumeration areas, sample units were selected. Accordingly, the necessary total sample size was determined to be about 2.2 million households (approximately $11.7 \%$ of total households). In addition, complete enumeration was realized in institutional places (university dormitories, nursing homes, prisons, orphanages, military barracks etc.). As a result, 9 million people (12\% of the total population) were interviewed with both CAPI $(60 \%)$ and PAPI (40\%) techniques. Regional offices of TurkStat performed the field study, under the coordination of the Central Office. Approximately 3,600 enumerators and 400 controllers were hired for this work [10]. In the 2011 PHC, the ABPRS was used for both obtaining $20 \%$ of the variables in the PHC and for the framework of a representative population sample. Besides the ABPRS, some other administrative data (e.g., Social Security Institution registers, Turkish Employment Agency registers and municipalities' building permits) were used to check and improve the quality of the field data and to impute missing observations.

With this new method, the number of field staff needed for collecting data was less than in previous traditional censuses. This provided significant advantages, such as lower cost, better quality of staff, and improved management and logistical operations. For instance, the total cost of 2000 population census was 48.3 million USD, while the 2011 PHC cost was 13.9 million USD. Accordingly, per capita costs decreased from 0.71 USD to 0.19 USD. Netbook usage (CAPI) provided some crosschecks between answers at the time of the interview, which also increased data quality and minimized missing data. Netbook usage for data collection resulted in better efficiency of time compared to other methods (e.g., ICR, manual data entry). In addition, due to CAPI application, data analyses could begin simultaneously with enumeration. Thus, for the 2011 PHC, the main results were published 1.5 years after the completion of enumeration. In contrast, using the traditional method only, results from the 2000 population census were published 2.5 years after enumeration. With timely online data transfer, field applications could be monitored daily and actively guided through the central system. Furthermore, using the ABPRS reduced the response burden, and utilizing unique ID numbers prevented duplications.

At each field-visit by an enumerator, respondents were asked to recall information from an earlier date (reference date). Due to the data collection period, the gap between the field-visit date and reference date could be up to three months. This caused some issues in the accuracy of recall. Although the use of netbooks provided many benefits, such as better time use and data quality, some problems still occurred in practice. For example, there was a tendency of the enumerators to tick "no" to the first (filter) question in a set of associated questions (e.g., migration and labor force questions) in the netbook application. Because the software was designed to automatically skip the related consecutive questions if the filter question was answered "no," this resulted in some missing observations. In contrast, when the paper form was used, it was observed that controllers (or data entry operators) could easily notice these kinds of systematic errors and correct them.

\section{Transformation needs: Forces driving the need for a register-based census}

There are a number of demands driving TurkStat to change its census methodology: the need to produce timelier, more useful and less costly annual population statistics; negative features of previous census methodologies (traditional or combined); improvements in administrative registers; society's expectations for more frequent, better quality, comprehensive statistics; and 


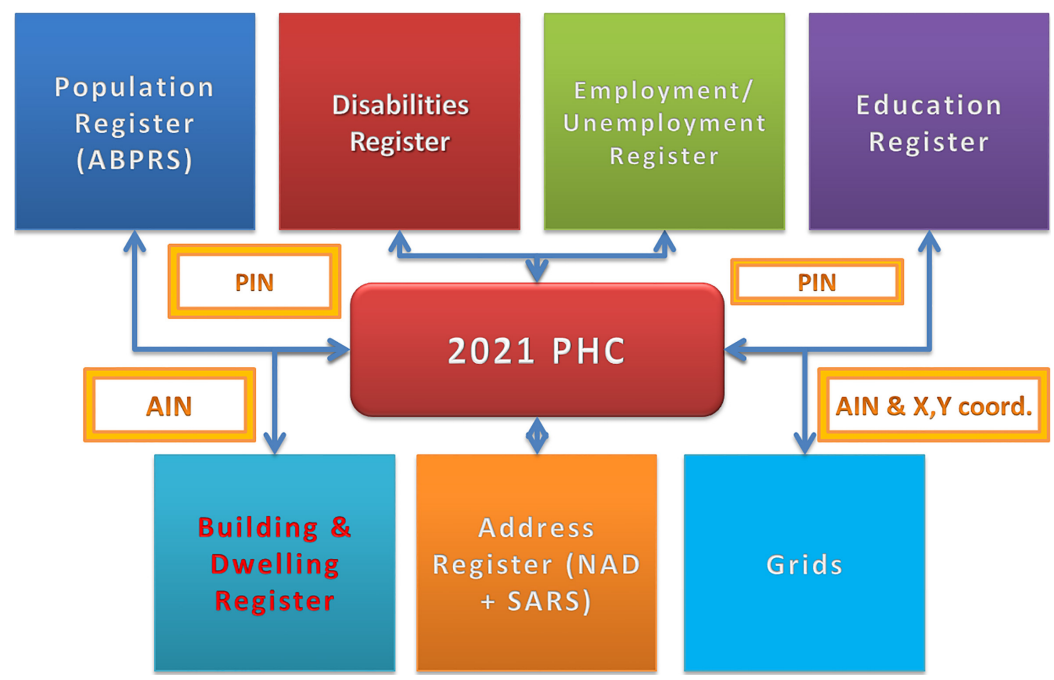

Fig. 2. Targeted system: Population characteristics database.

Eurostat's goal of producing a selected set of annual census statistics in the post-2024 period.

There are significant disadvantages to utilizing field study in population censuses. High on this list is the need for a large number of staff and the difficulty in hiring and training them for short-term work. An associated consideration is the difficulty in collecting data on mortality, labor force, and migration with inexperienced staff. Other important factors are the high cost, long duration of data processing, not being able to produce estimations for small geographic levels with sample survey studies (i.e., combined method), and rising concern about confidentiality and privacy. There is also a lack of interest and support from the municipalities, because their share of the general budget tax revenue is based on the ABPRS (i.e., they no longer see a need for a census). The high cost should be considered separately because the cost of conducting a full enumeration census is almost equal to the cost of creating a registration system based on field data. For this reason, TurkStat preferred to set up a registration system that can be used to produce statistics regularly, instead of spending time and money for a census, which cannot be updated.

On the other hand, for TurkStat, there are considerable factors driving them to implement a register-based census. This includes completion of the Central Civil Registration System (MERNIS), including unique ID numbers (2002), NAD (2006), ABPRS (2007), National Education Statistics Database (2008), Institutional Living Quarters Address Database (2012), and developments in the related administrative registers. In addition, the NAD is being transformed to the Spatial
Address Registration System (SARS) by adding coordinate information to addresses (overseen by the Ministry of Interior, during the 2012 to 2020 term). Twelve years of experience (2007 to 2018) in producing population statistics based on administrative data, and considerable experience in using registers for census purposes in the 2011 PHC, have encouraged TurkStat to realize a revolution in its census methodology.

Furthermore, there is a global trend for governments to move away from traditional or combined census methods, in favor of register-based censuses. In particular, this trend is being influenced by Eurostat's post 2021 goals. Thus, according to a report by the United Nations Economic Commission for Europe (UNECE), which surveyed its members methodology plans for the 2020 census round, there will be an increase in the adoption of register-based censuses from 9 countries in 2010 to 14 countries in 2020 [11].

\section{Target: Register-based census}

In its pursuit of timelier, more useful and less costly annual population statistics, Turkey plans to conduct a register-based census for the 2021 PHC. This method will allow TurkStat to publish census variables annually. Furthermore, TurkStat aims to use the 2021 PHC data to produce $1 \mathrm{~km}^{2}$ grid statistics.

To achieve this goal, it is obvious that some basic registers need to be made available, such as population (e.g., demography, migration, and household), address, education, employment, and building and dwelling registers. Figure 2 illustrates this "targeted 
system." This integrated system is known as the Population Characteristics Database (PCD). The intention of TurkStat is to add some other individual-related registers (i.e., tax, income, and social transfer records) to this system. Accordingly, TurkStat have been carrying out studies, in coordination with the relevant institutions, to produce statistics from administrative data. In particular, they are working toward producing labor force statistics and building and dwelling statistics because, unlike the address, population and education registers, single and complete (all requested attributes for all units) administrative data sources are not available for these topics.

\section{Preparations}

In preparation for the 2021 PHC, TurkStat have carried out various activities for different purposes. These activities can be categorized into five areas: legal framework, internal organization, increasing the level of knowledge among census staff, producing new census-type statistics, and pilot studies.

\subsection{Legal framework}

TurkStat included the $2021 \mathrm{PHC}$ and related issues (e.g., new census methodology and no more field application) into 2017 to 2021 OSP. In addition, the PCD, which is going to be the substructure of the registerbased census, has been added to the text of the 11th Development Plan (2019 to 2023) of Turkey.

\subsection{Internal organization (steering committee and working groups)}

Between 2014 and 2018, studies for the 2021 PHC were mainly carried out by the Population and Migration Statistics Group of TurkStat (under the Demographic Statistics Department) with the assistance of other departments. In May 2018, a steering committee (SC) was established to manage and coordinate all processes of the 2021 PHC. Working groups on Labor Force Statistics (November 2018) and Quality (January 2019) were established, according to the decisions of the SC. Due to the lack of an ideal registration system on building and dwelling characteristics, a special working group was established in January 2018 with the responsibility of executing all activities related to this subject.

\subsection{Increasing the level of knowledge among census staff}

In order to improve the technical skills and knowl- edge of census staff, the IPA 2015 Multi-beneficiary Statistical Cooperation Programme on Statistics provided valuable opportunities. Under this framework, TurkStat received technical consultancies on "Use of sample surveys as supplementary data source to register-based census" (November 2018) and "Development of long-term communication and outreach strategy" (March 2019). In addition, four TurkStat personnel attended courses on "Census quality assurance and evaluation" (December 2018) and "Statistical disclosure control of census data" (May 2019).

\subsection{Producing new census-type statistics}

TurkStat has been producing population statistics based on the ABPRS since 2007. This means that TurkStat has 12 collections of annual register-based population statistics. TurkStat's goal is to improve the system and increase the number of statistical topics produced. Therefore, studies on producing new census variables were carried out as part of 2021 PHC preparations. Possible methods for achieving this goal include integrating the existing administrative registers with the ABPRS, encoding the related data, and adding new topics to the registers with the assistance of the institutions that own the data. For instance, registers for literacy (2008), internal migration (2009), place of birth (for Turkish citizens in 2014 and for foreign-born population in 2015), types of households (2016), immigration and emigration (2018), internal migration for foreigners (2018) were produced as a result of such efforts.

With this goal in mind, negotiations with the Ministry of Interior were successfully completed and, as of November 2016, district civil registration offices began compiling information on "reasons for internal migration" as part of the address notification process. Analyses using other administrative records are ongoing, and TurkStat is planning to begin publication of these statistics in 2020.

\subsection{Pilot studies and related works}

For conducting a register-based census, currently available administrative or statistical registers on population, address, and education are sufficient to produce most of the desired census variables. However, complete and satisfactory registers on housing characteristics and economic characteristics (labor force status, industry etc.) of the population are not available. There are many subject specific registers that must be 
integrated in order to produce census statistics on these topics. However, it is not simply an issue of linking the related registers. There are also issues related to missing observations and quality assurance to overcome.

In terms of quality assurance, TurkStat tried to carry out some checks at the first stage, including content control, target population control, definitions of variables (for relevance and comparability), metadata control, missing data control, and some plausibility controls. To overcome conflicting situations between different administrative data sources, it is useful to have a hierarchy of register attributes, such as necessity, legal obligation, usability, penal sanction, and whether it is normative, easy to declare, well-protected, and confidential. But for a register-based census, it is clear that the quality of the registers should be evaluated comprehensively. For this reason, TurkStat is working on a general Risk Management Plan for the 2021 PHC.

For assessing the accuracy of the records, regular LFS data would be helpful since ABPRS data has already begun to be used in LFS. Therefore, it should now be easy to link the survey data with the administrative registers. Accordingly, TurkStat planned two separate pilot studies for the areas of "building and dwelling" and "labor force" statistics in the preparation process of the $2021 \mathrm{PHC}$.

\subsubsection{Studies on building and dwelling statistics}

For the development of a register for building and dwelling statistics, TurkStat, with the help of relevant institutions, prepared an inventory on possible existing registers to be used, including assessments on content and quality. Afterwards, a survey was conducted with all municipalities to understand the scope, content, and availability of municipal registers. A survey on "Building and Dwelling Registers of Municipalities" was carried out in November 2017 by the regional offices of TurkStat. This survey enquired about the existence of any kind of database, including data for buildings and dwellings, compliance to the address register, and content. The results of the survey revealed that municipal sources alone are not sufficient for establishing a database for building and dwelling characteristics. Furthermore, the survey results, and interviews with the municipalities, indicate that the validity of the old records is suspicious in some aspects. Some of the characteristics of a building may have changed but not been updated in the registers. For example, although major modifications to buildings require a new building permit, people often avoid getting the permit, especially in rural areas. Therefore, information that changes over time, such as heating system and ownership, should be crosschecked with other related registers.

TurkStat should gather all usable records from the relevant sources to assess the current situation clearly. A pilot study was carried out in February to March 2018 in order to determine the availability, coverage, and feasibility of using existing records. This pilot study was conducted for the Afyonkarahisar province municipality, which has a population of 230,000 people and where SARS is already in use. All available registers (building permits, property tax records, land registry and cadaster information system records, compulsory earthquake insurance records, subscription records of electricity, tap water etc.) were obtained from relevant organizations in electronic format. These records were linked to SARS by using both conventional methods (e.g., ID number) and geographical information system methods.

According to the pilot study results, the proportion of records that matched to SARS from other data sources was $97.8 \%$ for building permits, $90.8 \%$ for property tax records, $100 \%$ for land registry and cadaster information system records, and $80 \%$ for compulsory earthquake insurance records. Calculations made from the records that matched to SARS showed that the coverage ratios of the data sources were $22.3 \%$ for building permits, $64.7 \%$ for property tax records, $98.7 \%$ for land registry and cadaster information system records, and $14.5 \%$ for compulsory earthquake insurance records. Consequently, it was determined that existing data sources are not sufficient to establish a database to be used as an administrative registration system for building and dwellings. However, they would be useful for statistical purposes.

\subsubsection{Studies on labor force statistics}

TurkStat started a pilot study on register-based labor force statistics in May 2019. The main goal of the study is to determine the possibility of producing labor force statistics from administrative registers. The reference date of the study was 31 December 2018. In the first stage of the study, registers of the Social Security Institution (e.g., insured persons and pensioners), Turkish Employment Agency (job seekers), Higher Education Council and Ministry of Education (enrolled students), Ministry of Family, Labor and Social Services (disabled people), and the Ministry of Treasury and Finance (tax and income) were used with the Farmer Registration System and Tradesmen Information System. The first stage was completed in July 2019 and in- 
volved linking all available registers with the ABPRS. Some conflicts between related registers and inconsistencies with the census definitions were identified. In Turkey, the Employment Agency keeps the registration records of job-seekers who are expected to upload required information like education, occupation to the system completely and accurately. Legally, every Turkish citizen or foreigner with a working permit can apply for work, whether they are already in employment or not. There may also be delays in updating the registers. Furthermore, some people work in different jobs at the same time, and these jobs may be related to different insurance systems. Consequently, these issues cause duplicated records in the integrated database. Therefore, TurkStat had to resolve these kinds of issues, mainly by applying the priority rules (hierarchy) between registers.

After linkage, the main outcomes like employment rate, employment status, etc were compared with the labor force survey statistics to evaluate consistency. According to the results of this stage of the pilot study, it was found that there is some under-coverage in employment and shifts between employers and selfemployed persons. Furthermore, it was understood that the Turkish Employment Agency records, which is the main administrative data source on unemployment, is inadequate for producing statistics on this subject. That is why TurkStat decided to develop additional registers to support the above mentioned administrative data. One of the most important achievements of the pilot study was that TurkStat identified the shortcomings and problems in the registers, which will provide insights for future work.

\section{Conclusions}

According to the results of the pilot study on building and dwelling statistics, it was seen that existing data sources are not sufficient for establishing a database on building and dwellings to be used as an administrative registration system. Therefore, missing data should be collected through special field work or should be entered in the address register by the relevant municipality. In order to meet this requirement, political decision-making is needed for two reasons: the high cost of enumeration and keeping the system up-to-date by ensuring the participation of relevant institutions. If no such decision will be taken, TurkStat will need to establish a statistical database to fill the gap.
For producing statistics on economic characteristics of the population, results of the first stage of the pilot study on register-based labor force statistics showed that TurkStat needs more detailed registers, such as data for pensioners and dependents under the social security system. Moreover, supplementary sources should be used to support the Employment Agency records on unemployment. TurkStat must also solve the missing observation issues in the administration data. Hence, TurkStat must determine proper estimation methods for missing data in integrated administrative data sources. Here it is critical to identify the predictive variables and to decide the method to be used. Fortunately, TurkStat has a plan to resolve this issue with the help of academics and data holder institutions.

With respect to the to the UNECE recommendations for the 2020 Censuses of Population and Housing [12], and EU legislation [13], TurkStat is likely to produce approximately $70 \%$ of the core census topics using the currently available registers. And of course, TurkStat will continue its efforts to produce the remaining census statistics, especially by using and improving other existing registers. Since the system has been designed for improvement, and because the number of statistical topics produced from population registers will increase continuously, changing Turkey's population census methodology is not an opportunity but an obligation.

\section{References}

[1] United Nations, Department of Economic and Social Affairs, Population Division. World Population Prospects, 2019. [Online Edition]. Available from: https://population.un.org/wpp/.

[2] Eurostat Database, Population on 1 January, DEMO_GIND [Internet]. Ec.europa.eu. 2019 [cited 28 August 2019]. Available from: https://ec.europa.eu/eurostat/databrowser/view/tps 00001/default/table?lang=en.

[3] United States Census Bureau. International Programs - Information Gateway - U.S. Census Bureau [Internet]. International Database. 2019 [cited 28 August 2019]. Available from: https://www.census.gov/data-tools/demo/idb/informationGa teway.php.

[4] Turkish Statistical Institute. Official Statistics Programme, 2017-2021. 2017; ISBN 978-975-19-6715-2. Available from: http://www.officialstatistics.gov.tr/.

[5] İnalcık H, Pamuk Ş, editors. Data and statistics in the Ottoman Empire. State Institute of Statistics Prime Ministry Republic of Turkey. 2000; ISBN 975-19-2594-0.

[6] Karal EZ, Osmanlı İmparatorluğunda İlk Nüfus Sayımı 1831 (The First Population Census in the Ottoman Empire 1831). State Institute of Statistics Prime Ministry Republic of Turkey, 1997. 
[7] State Institute of Statistics Prime Ministry Republic of Turkey 2000 Census of Population Social and Economic Characteristics of Population Turkey. 2003; ISBN 975-19-3338-2.

[8] Ministry of Interior of Turkey, General Directorate of Civil Registration and Nationality. MERNIS [Internet]. 2019 [cited 28 August 2019]. Available from: https://www.nvi.gov.tr/ mernis.

[9] Turkish Statistical Institute Official Web Site. Address Based Population Registration System [Internet]. 2019 [cited 28 August 2019]. Available from: http://www.turkstat.gov.tr/Pre Tablo.do?alt_id=1059.

[10] Turkish Statistical Institute. Population and Housing Census 2011. 2013; ISBN 978-975-19-5802-0

[11] Valente P. From the 2010 to the 2020 census round in the UNECE region - Plans by countries on census method- ology and technology. 2015; Economic Commission for Europe, Conference of European Statisticians, Group of Experts on Population and Housing Censuses, Seventeenth Meeting, Geneva, 30 September to 2 October 2015 [ECE/CES/GE.41/2015/WP.24]. Available from: https://www .unece.org/fileadmin/DAM/stats/documents/ece/ces/ge.41/ 2015/mtg1/UNECE_paper_Paolo_draft_0925_rev2.pdf.

[12] United Nations Economic Commission for Europe (UNECE). Conference of European Statisticians recommendations for the 2020 censuses of population and housing. New York and Geneva: United Nations, 2015.

[13] Eurostat. EU legislation on the 2021 population and housing censuses Explanatory Notes. Luxembourg: Publications Office of the European Union; 2019. 